OPEN ACCESS

Edited by:

Pietro Mesirca,

INSERM U1191 Institut

de Génomique Fonctionnelle (IGF),

France

Reviewed by:

Tatiana M. Vinogradova,

National Institute on Aging, National

Institutes of Health $(\mathrm{NIH})$,

United States

Anna Moroni,

University of Milan, Italy

Wayne Rodney Giles,

University of Calgary, Canada

*Correspondence:

Stefanie Fenske

stefanie.fenske@cup.uni-

muenchen.de

Christian Wahl-Schot wahl-schott.christian@mh-

hannover.de

Specialty section:

This article was submitted to

Cardiac Electrophysiology,

a section of the journal

Frontiers in Physiology

Received: 17 February 2021

Accepted: 19 April 2021

Published: 27 May 2021

Citation:

Hennis K, Rötzer RD, Piantoni C Biel M, Wahl-Schott $C$ and Fenske $S$

(2021) Speeding Up the Heart? Traditional and New Perspectives on

HCN4 Function.

Front. Physiol. 12:669029.

doi: 10.3389/fphys.2021.669029

\section{Speeding Up the Heart? Traditional and New Perspectives on HCN4 Function}

\author{
Konstantin Hennis ${ }^{1}$, René D. Rötzer ${ }^{1}$, Chiara Piantoni², Martin Biel'1,3, \\ Christian Wahl-Schott ${ }^{2,3 *}$ and Stefanie Fenske ${ }^{1,3 *}$
}

${ }^{1}$ Center for Drug Research, Department of Pharmacy, Ludwig-Maximilians-Universität München, Munich, Germany, 2 Institute for Neurophysiology, Hannover Medical School, Hanover, Germany, ${ }^{3}$ German Center for Cardiovascular Research (DZHK), Partner Site Munich Heart Alliance, Munich, Germany

The sinoatrial node (SAN) is the primary pacemaker of the heart and is responsible for generating the intrinsic heartbeat. Within the SAN, spontaneously active pacemaker cells initiate the electrical activity that causes the contraction of all cardiomyocytes. The firing rate of pacemaker cells depends on the slow diastolic depolarization (SDD) and determines the intrinsic heart rate (HR). To adapt cardiac output to varying physical demands, HR is regulated by the autonomic nervous system (ANS). The sympathetic and parasympathetic branches of the ANS innervate the SAN and regulate the firing rate of pacemaker cells by accelerating or decelerating SDD-a process well-known as the chronotropic effect. Although this process is of fundamental physiological relevance, it is still incompletely understood how it is mediated at the subcellular level. Over the past 20 years, most of the work to resolve the underlying cellular mechanisms has made use of genetically engineered mouse models. In this review, we focus on the findings from these mouse studies regarding the cellular mechanisms involved in the generation and regulation of the heartbeat, with particular focus on the highly debated role of the hyperpolarization-activated cyclic nucleotide-gated cation channel HCN4 in mediating the chronotropic effect. By focusing on experimental data obtained in mice and humans, but not in other species, we outline how findings obtained in mice relate to human physiology and pathophysiology and provide specific information on how dysfunction or loss of HCN4 channels leads to human SAN disease.

Keywords: sinoatrial node, pacemaking, chronotropic effect, heart rate regulation, autonomic nervous system, HCN4 channel, cyclic nucleotide-gated (HCN) channels, hyperpolarization-activated cation channel

\footnotetext{
Abbreviations: ANS, autonomic nervous system; CaMKII, $\mathrm{Ca}^{2+} /$ calmodulin-dependent protein kinase II; cAMP, cyclic adenosine monophosphate; CNBD, cyclic nucleotide-binding domain; ECG, electrocardiogram; FRET, Förster resonance energy transfer; GIRK, G protein-coupled inwardly rectifying potassium channel; HCN channel, hyperpolarization-activated cyclic-nucleotide gated cation channel; HR, heart rate; LCR, local calcium release; NCX, sodium-calcium exchanger; PKA, protein kinase A; RyR, ryanodine receptor; SAN, sinoatrial node; SDD, slow diastolic depolarization; SERCA, sarco-/endoplasmic reticulum $\mathrm{Ca}^{2+}$ ATPase; SR, sarcoplasmic reticulum; WT, wild type.
} 


\section{INTRODUCTION}

\section{Anatomy and Structure of the Sinoatrial Node and Sinoatrial Node Network}

The sinoatrial node (SAN) is a spindle-shaped structure located at the posterior side of the right atrium of the heart (Figure 1). It runs from the superior vena cava along the sulcus terminalis toward the inferior vena cava (Liu et al., 2007). The cranial portion is referred to as the sinus node "head," the middle portion as the "body," and the caudal portion as the "tail" (SanchezQuintana et al., 2005). In the mouse, the SAN is extremely small with a longitudinal dimension along the crista terminalis of about $500-1000 \mu \mathrm{m}$ and a width of approximately $150 \mu \mathrm{m}$ (Verheijck et al., 2001; Liu et al., 2007). In humans, the dimensions of the SAN are naturally larger with a length along the crista terminalis of approximately $14-15 \mathrm{~mm}$, a width of 6-7 $\mathrm{mm}$, and a thickness of about $1 \mathrm{~mm}$ (Fedorov et al., 2010).

The SAN network is composed of different cell types comprising spontaneously active pacemaker cells that are interspersed with fibroblasts and embedded within a matrix of fibrous connective tissue, predominately consisting of elastin and collagen (Monfredi et al., 2010; Ho and Sanchez-Quintana, 2016). Pacemaker cells are electrically coupled to each other via gap junctions. In addition, there are electrical connections between pacemaker cells, atrial cardiomyocytes and macrophages residing in the SAN. The pacemaker cells also have synaptic contacts with the nerve endings of the sympathetic nerve and vagus nerve, through which the activity of the cells can be changed and controlled (Verheijck et al., 2002; Camelliti et al., 2004; Pauza et al., 2014; Hulsmans et al., 2017). It is now known that the functional interactions of individual pacemaker cells in this cellular network with each other and with the other cell types in the network are of general importance for electrical synchronization to a common electrical rhythm of the sinus node. The slow diastolic depolarization (SDD) is a unique feature of pacemaker cells that drives generation of spontaneous and rhythmic action potentials (Figure 2). After completion of the repolarization, pacemaker cells in the SAN do not remain at a stable resting membrane potential but instead slowly depolarize the membrane toward a threshold potential at which the next

\section{A}

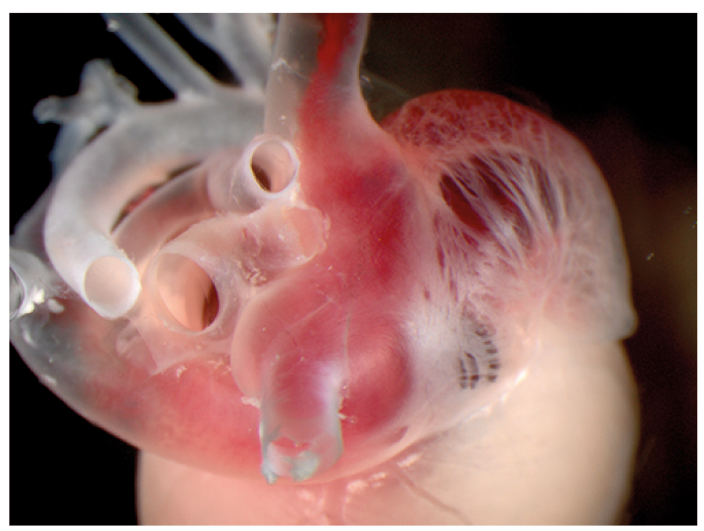

B

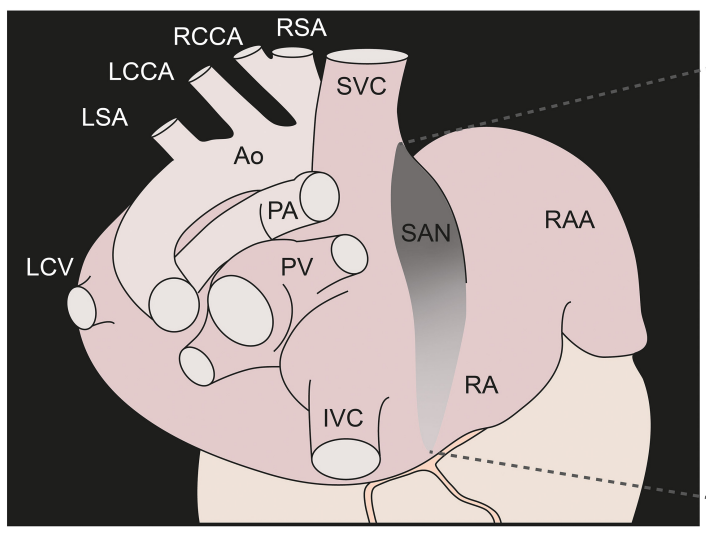

C

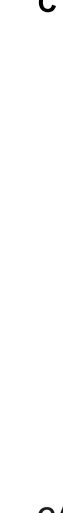

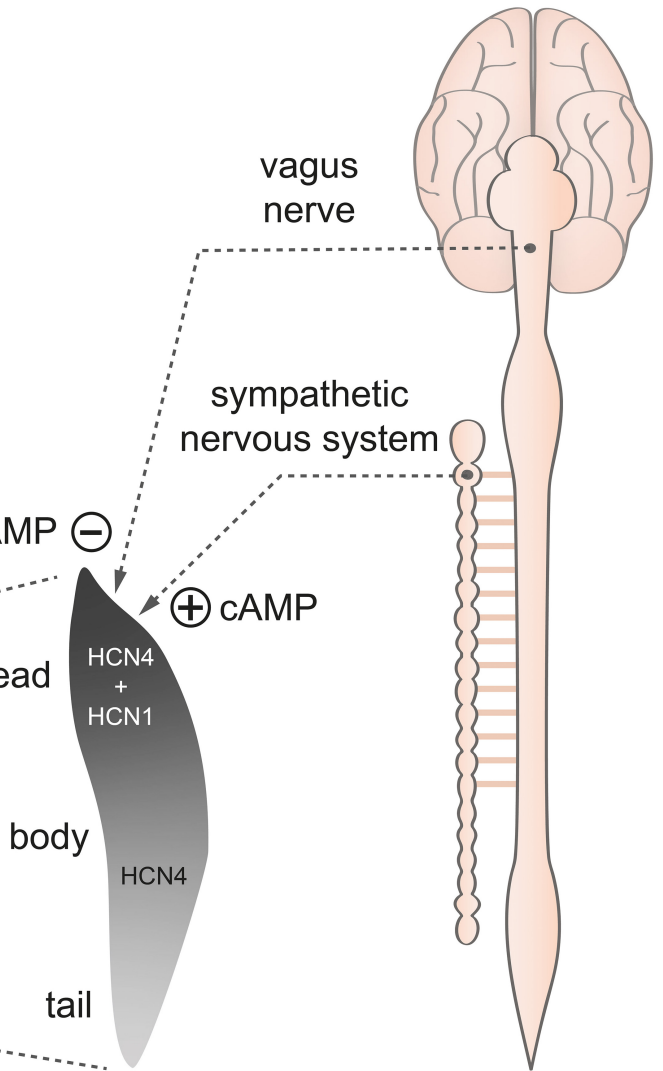

FIGURE 1 | The sinoatrial node. (A) Dorsolateral view of the sinoatrial node region of a gelatine-filled mouse heart. (B) Schematic illustration of the heart shown in panel (A), depicting the location of the sinoatrial node (SAN) (gray) within the right atrium (RA). (C, left) Magnification of the SAN region. The cranial portion is referred to as the sinus node "head," the middle portion as the "body," and the caudal portion as the "tail." HCN1 channels are only expressed in the head region whereas HCN4 channels are expressed throughout the whole SAN. (C, right) The SAN is innervated by the sympathetic and parasympathetic nervous system (dashed lines). Activity of both ANS branches tightly controls cAMP concentration in SAN cells. Abbreviations: Ao, Aorta; IVC, inferior vena cava; LCCA, left common carotid artery; LCV, left cranial vein; LSA; left subclavian artery; PA, pulmonary arteries; PV, pulmonary veins; RAA, right atrial appendage; RCCA, right common carotid artery; RSA, right subclavian artery; SVC, superior vena cava. Figure is adapted from Hennis et al., 2021. 


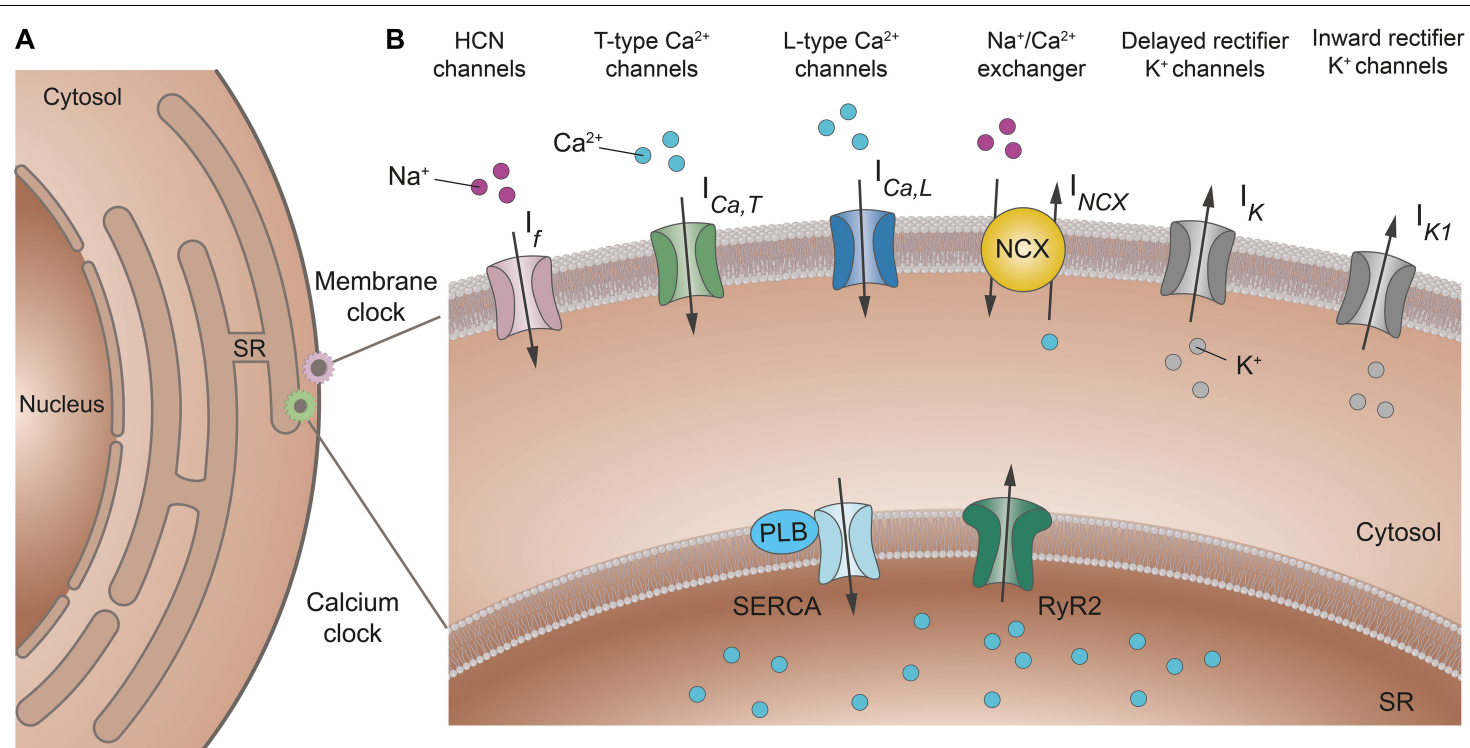

C

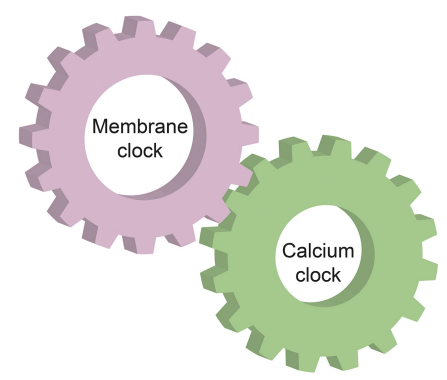

E

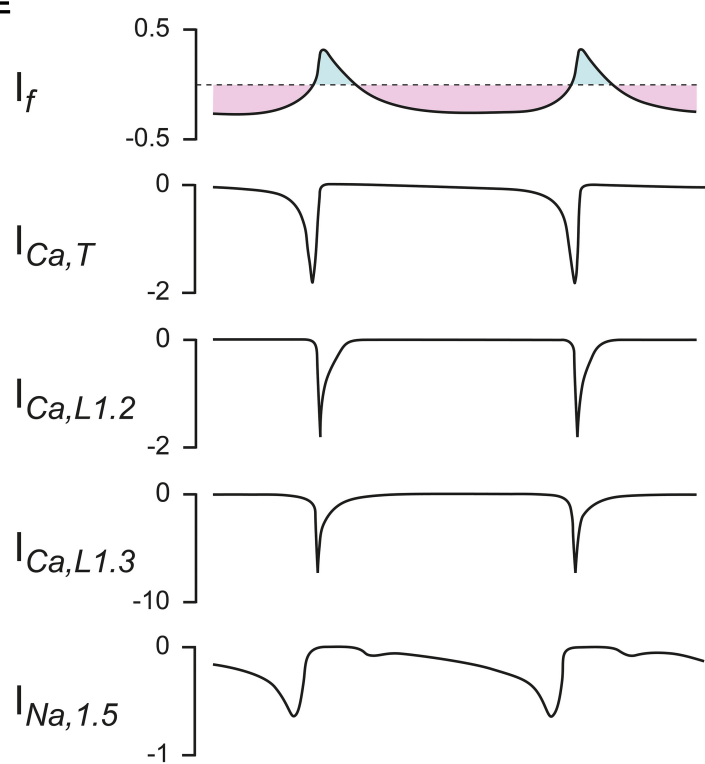

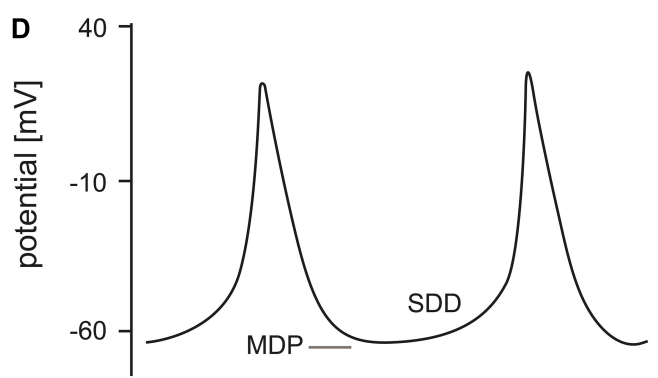
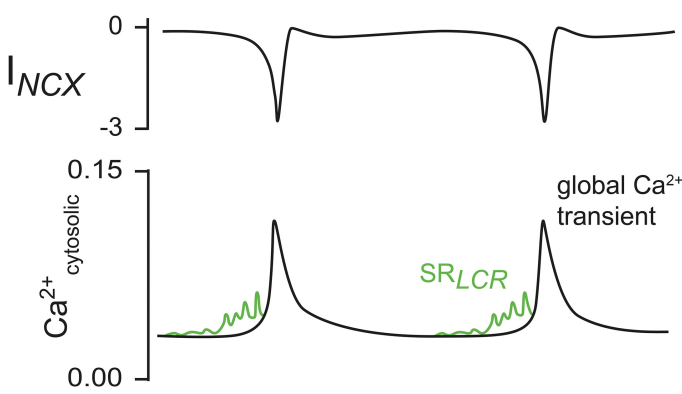

FIGURE 2 | Membrane and calcium clock contribute to the generation of SDD. (A) Schematic representation of a SAN cell containing the nucleus, cytosol, and sarcoplasmic reticulum (SR). (B) Section of the cell with a magnified view of the plasma membrane and SR membrane. Various proteins that contribute to SDD and are localized in the plasma membrane are collectively described as the membrane clock. These include hyperpolarization-activated cyclic-nucleotide gated (HCN) cation channels (pink), T-type $\mathrm{Ca}^{2+}$ channels (green), L-type $\mathrm{Ca}^{2+}$ channels (blue), $\mathrm{Na}^{+} / \mathrm{Ca}^{2+}$ exchanger proteins ( $\mathrm{NCX}$, yellow), rapid and slow delayed rectifier $\mathrm{K}^{+}$ channels (gray), and inward rectifier $\mathrm{K}^{+}$channels (gray). The corresponding ionic currents (I) are indicated. Intracellular $\mathrm{Ca}^{2+}$ cycling events that contribute to the pacemaker process are summarized as calcium clock. Among them are sarco-/endoplasmic reticulum $\mathrm{Ca}^{2+}$ ATPases (SERCA) (light blue) associated with the regulatory protein phospholamban (PLB) and ryanodine receptors (RyR2) (dark green) located in the SR membrane. (C) Functional interaction of the membrane 


\section{FIGURE 2 | Continued}

clock and calcium clock is required to ensure regular and rhythmic excitation of the cells. (D) Spontaneous SAN action potentials with the characteristic slow diastolic depolarization phase (SDD). The maximum diastolic potential (MDP) is indicated. (E) Relative contribution of the ionic currents responsible for SDD and spontaneous action potential firing in mouse SAN cells according to the mathematical model published by Kharche et al. (2011). Current amplitudes are normalized to the cell capacitance (in units of pA/pF). (Upper left panel) $I_{f}$ manifests as a mainly time-independent, but bidirectionally flowing current. The inward (light purple) and outward component (light blue) are indicated. (Lower right panel) Sarcoplasmic reticulum local calcium releases (SR LCR $_{\text {) }}(\mathrm{green}$ ) that characteristically occur during late SDD have been added to the model data for cytosolic $\mathrm{Ca}^{2+}$ transients according to Lakatta et al. (2010). Abbreviations: $\mathrm{I}_{\mathrm{f}}$, hyperpolarization-activated

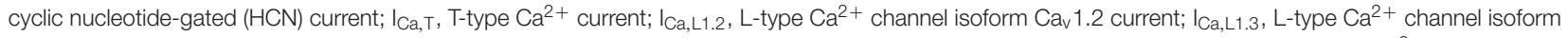
$\mathrm{Ca}_{\mathrm{V}} 1.3$ current; $\mathrm{I}_{\mathrm{Na}, 1.5}, \mathrm{Na}^{+}$channel isoform Nav1.5 current; $\mathrm{I}_{\mathrm{K} 1}$, inward rectifying $\mathrm{K}^{+}$current; $\mathrm{I}_{\mathrm{K}}$, delayed rectifying $\mathrm{K}^{+}$current; $I_{\mathrm{NCX}}, \mathrm{Na}^{+} / \mathrm{Ca}^{2+}$ exchanger current; $\mathrm{Ca}^{2+}$ cytosolic, cytosolic $\mathrm{Ca}^{2+}$ concentration; LCR, local calcium release. For further details see text. Figure is adapted from Lakatta et al. (2010), Kharche et al. (2011), Cingolani et al. (2018).

action potential is generated (Figure 2D). The slope of SDD essentially determines the duration of the pacemaker cycle and thus the heart rate (HR).

\section{HCN Channels Are Markers for the SAN}

Marker proteins for pacemaker cells within the SAN are hyperpolarization-activated cyclic nucleotide-gated (HCN) channels, of which four isoforms (HCN1-4) exist in mammals. $\mathrm{HCN}$ channels belong to the superfamily of voltage-gated cation channels. Four HCN subunits are assembled around a central ion-conducting pore. Each of the subunits consists of six $\alpha$-helical transmembrane segments (S1-6) and the intracellular $\mathrm{N}$ - and C-termini. $\mathrm{HCN}$ channels are opened by hyperpolarization and are the molecular determinants of the ionic current $I_{f}$ in pacemaker cells (Ludwig et al., 1998; Mangoni and Nargeot, 2008; Biel et al., 2009; Li et al., 2015). The channel properties can be modulated by binding of the cyclic nucleotide cyclic adenosine monophosphate (cAMP) to a cyclic nucleotide-binding domain (CNBD) in the C-terminus of the channel (Zagotta et al., 2003), thereby facilitating channel opening. The different isoforms are characterized by some different features, such as kinetics, voltage dependence and cAMP modulation. For example, HCN4 displays the slowest activation and deactivation kinetics and opens at more negative potentials than the other isoforms (Wahl-Schott and Biel, 2009). In contrast, HCN1 displays the fastest kinetics and opens at more positive potentials. Furthermore, HCN4 is the most sensitive to the second messenger cyclic AMP, while the subtype HCN1 is only weakly affected by cAMP (Wahl-Schott and Biel, 2009).

In the mouse, HCN4 is the predominant isoform expressed in pacemaker cells throughout the SAN, whereas HCN1 channels are expressed only in the head region (Fenske et al., 2013). HCN2 channels are expressed only very weakly and are anatomically restricted to the periphery of the SAN (Liu et al., 2007; Herrmann et al., 2011; Fenske et al., 2013).

In humans, $\mathrm{HCN} 4, \mathrm{HCN} 1$, and $\mathrm{HCN} 2$ channels are expressed uniformly throughout the SAN without any of the isoforms being restricted to a particular region (Li et al., 2015). Importantly, $\mathrm{HCN} 1$ is almost exclusively expressed in the SAN, while HCN2 and HCN4 are present both in SAN pacemaker cells and surrounding right atrial myocytes. Therefore, despite being the predominant isoform also in human SAN, HCN4 cannot be used as a unique marker to identify human SAN pacemaker cells (Chandler et al., 2009; Kalyanasundaram et al., 2019).
Since its first discovery, the $\mathrm{I}_{\mathrm{f}}$ current and its role in cardiac pacemaking have been highly debated, leading to controversial views on the importance of $\mathrm{I}_{\mathrm{f}}$ in pacemaker activity. On the one side, several groups have questioned a direct involvement of $I_{f}$ in the generation of action potentials because of its negative threshold of activation and slow time constant (Noma et al., 1980; Yanagihara and Irisawa, 1980), suggesting that the purpose of the current is more likely to maintain a low membrane potential in pacemaker cells. Furthermore, Noma and collaborators showed that $\mathrm{Cs}^{+}$reversibly blocks $\mathrm{I}_{\mathrm{f}}$ but does not significantly affect the rate of pacemaking (Noma et al., 1983). On the other side, Denyer and Brown (1990) strongly suggested that the $\mathrm{I}_{\mathrm{f}}$ current normally makes an important contribution to the depolarization of all SAN pacemaker cells, while the groups of Kreitner (1985); Nikmaram et al. (1997) described a possible different role of $\mathrm{I}_{\mathrm{f}}$ in different SAN regions with a greater influence in the periphery than in the center of the SAN.

\section{SPONTANEOUS ACTIVITY OF SINOATRIAL NODE PACEMAKER CELLS}

The ability of SAN pacemaker cells to generate SDD and spontaneous action potentials has been attributed to the interplay of two major cellular mechanisms named membrane clock and calcium clock (Figures 2A-C; Lakatta et al., 2010). Insights into these mechanisms are derived from experimental data obtained in mice, which are also the basis for mathematical models of action potential firing in mouse SAN cells (Figures 2D,E; Kharche et al., 2011).

The membrane clock comprises the activity of all ion channels and transporters that are localized in the cell membrane and contribute to the membrane potential characteristics of SDD (Figures 2D,E). Following termination of an action potential, when the membrane potential is most negative (maximum diastolic potential), the early phase of SDD is initiated by the depolarizing inward current $\mathrm{I}_{\mathrm{f}}$ that is mediated by constitutively open HCN channels and persists throughout the range of SDD (DiFrancesco et al., 1986; DiFrancesco, 1993; Mangoni and Nargeot, 2008; Biel et al., 2009). The $\mathrm{I}_{\mathrm{f}}$ current drives the membrane potential toward the threshold potential at which voltage-gated T-type $\left(\mathrm{Ca}_{V} 3.1\right)$ and L-type $\left(\mathrm{Ca}_{\mathrm{V}} 1.3\right) \mathrm{Ca}^{2+}$ channels are activated. In addition, voltage-gated sodium channels $\left(\mathrm{I}_{\mathrm{Na}, 1.5}\right.$, Figure $2 \mathrm{E}$ ) contribute to membrane depolarization during late SDD and the action potential upstroke. 
Sodium currents have been shown to be involved in both pacemaking and impulse conduction within the SAN of mice as well as humans, although there seem to be profound speciesdependent differences regarding the contribution of different sodium channel isoforms (Lei et al., 2004, 2007; Li et al., 2020). The combination of all inward currents further depolarizes the membrane during late SDD, which leads to an additional opening of voltage-gated L-type $\mathrm{Ca}_{\mathrm{V}} 1.2$ channels. $\mathrm{I}_{\mathrm{Ca}, L}$ mainly generates the action potential upstroke and is responsible for coupling excitation to contraction (electromechanical coupling): $\mathrm{Ca}^{2+}$ entering cardiomyocytes via Cav 1.2 activates ryanodine receptor 2 (RyR2) which initiates global intracellular $\mathrm{Ca}^{2+}$ release from the sarcoplasmic reticulum (SR) (calcium-induced calcium release) and triggers myofibril contraction. Depolarization of the membrane inactivates voltage-gated calcium currents and activates delayed rectifier potassium channels, which conduct the outward currents $I_{K, r}$ and $I_{K, s}$ that are responsible for membrane repolarization and action potential termination (Figure 2B,E; Mangoni and Nargeot, 2008; Mesirca et al., 2021). At the beginning of the following pacemaker cycle, the decay of outward potassium currents due to time- and voltage-dependent inactivation of $\mathrm{I}_{\mathrm{K}, \mathrm{r}}$ and $\mathrm{I}_{\mathrm{K}, \mathrm{s}}$ allows the inward pacemaker currents to depolarize the membrane and thus represents another key component of early SDD (Irisawa et al., 1993). Moreover, the inward rectifier potassium current $\mathrm{I}_{\mathrm{K} 1}$ is prominently expressed in murine SAN cells (Figures 2B,E), whereas $\mathrm{I}_{\mathrm{K} 1}$ is small or absent in human SAN (Chandler et al., 2009). This might be a reason why membrane potentials in human SAN cells are more positive, which would indirectly support pacemaking (Dobrev, 2009).

In addition to the membrane clock, intracellular $\mathrm{Ca}^{2+}$ cycling events take place that may significantly contribute to the pacemaker process and are summarized as calcium clock (Figures 2A-C; Lakatta et al., 2010). During late SDD, periodically occurring, rhythmic local calcium release events (LCRs) from the SR are mediated by spontaneous opening of RyR2 (Vinogradova et al., 2004). The resulting increase in the intracellular $\mathrm{Ca}^{2+}$ concentration activates the sodiumcalcium exchanger (NCX), a transporter located in the cell membrane that extrudes one $\mathrm{Ca}^{2+}$ ion out of the cell in exchange for three $\mathrm{Na}^{+}$ions entering the cell when operating in its forward mode (Figures 2B,E; Mangoni and Nargeot, 2008). Since in cardiac myocytes the reversal potential of NCX is about $-20 \mathrm{mV}$ (Bers et al., 1988; Baartscheer et al., 2011), the outward transport of $\mathrm{Ca}^{2+}$ coupled to inward transport of $\mathrm{Na}^{+}$(forward mode) is favored in the diastolic range of membrane potentials. This causes a net inward current $\left(\mathrm{I}_{\mathrm{NCX}}\right)$ which further depolarizes the membrane and is responsible for the exponential increase in membrane potential during the late phase of SDD, immediately prior to the action potential upstroke (Figures 2D,E; Bogdanov et al., 2006). The extent of LCRs critically depends on SR $\mathrm{Ca}^{2+}$ load, which in turn is regulated by the activity of the sarco-/endoplasmic reticulum $\mathrm{Ca}^{2+}$ ATPase (SERCA) that refills the $\mathrm{SR} \mathrm{Ca}^{2+}$ stores after action potential termination (Vinogradova et al., 2010). The $\mathrm{Ca}^{2+}$ reuptake into the SR is significantly regulated by phospholamban, a 52-amino acid peptide directly inhibiting SERCA activity (Vinogradova et al., 2018). This calcium clock concept was mainly derived from confocal calcium imaging experiments in isolated cells of the SAN. Recently, it was strengthened by combined calcium imaging and electrophysiological experiments in human primary SAN pacemaker cells (Tsutsui et al., 2018). Together, the proper function of both the membrane clock and calcium clock processes as well as functional coupling of the underlying mechanisms are indispensable for the pacemaker process (Tsutsui et al., 2018). In addition, several proteins associated with the membrane clock or calcium clock are modulated by activity of the autonomic nervous system (ANS). Therefore, there are many potential candidates that could be involved in or mediate the chronotropic effect and $\mathrm{HR}$ regulation.

\section{DOES CAMP-DEPENDENT REGULATION OF HCN4 MEDIATE THE CHRONOTROPIC EFFECT?}

The ANS consists of the sympathetic nervous system and parasympathetic nervous system. Both branches of the ANS innervate the SAN (Pauza et al., 2014) and activate intracellular signal transduction cascades in SAN pacemaker cells that regulate HR (Figure 3). Following activation of the sympathetic nervous system, the neurotransmitter norepinephrine is released from nerve terminals and activates $G_{s}$ protein-coupled receptors. The subsequent stimulation of adenylyl cyclases increases the cytoplasmic concentration of the second messenger cAMP (Behar et al., 2016). cAMP binds to a variety of target proteins in the cell, which finally results in acceleration of SDD and consequently the firing rate of pacemaker cells and $\mathrm{HR}$ increase (positive chronotropic effect). In contrast, release of acetylcholine from parasympathetic nerve terminals inhibits adenylyl cyclase activity via activation of $\mathrm{G}_{i}$ protein-coupled receptors, followed by a reduction in the cytoplasmic cAMP concentration. In addition, acetylcholinedependent $\mathrm{G}_{\beta \gamma}$ signaling activates $\mathrm{G}$ protein-coupled inwardly rectifying potassium channels (GIRK1 and GIRK4) that conduct an outward current $\left(\mathrm{I}_{\mathrm{K}, \mathrm{ACh}}\right)$ which leads to membrane hyperpolarization. Together, this reduces the maximum diastolic potential and slope of SDD and as a consequence the firing rate and HR decrease (negative chronotropic effect). However, the exact signaling pathway by which alterations in intracellular cAMP mediate an increase or decrease in the firing frequency is still incompletely understood.

HCN4 channels, the main HCN channel isoform in the SAN, display several characteristics which make them an ideal target for HR regulation by the ANS. First, the channels are opened by hyperpolarization and conduct a depolarizing inward current $\left(\mathrm{I}_{\mathrm{f}}\right)$ throughout the time course of SDD, i.e., at membrane potentials negative to the channel's reversal potential (Mangoni and Nargeot, 2008; Biel et al., 2009). Second, activity of HCN4 is directly regulated by binding of cAMP (DiFrancesco and Tortora, 1991) to a CNBD (Zagotta et al., 2003) in the intracellular C-terminus of the channel (cAMP-dependent regulation, CDR) and is, hence, tightly controlled by the ANS. Consequently, it has been postulated for a long time that CDR of HCN4 
A
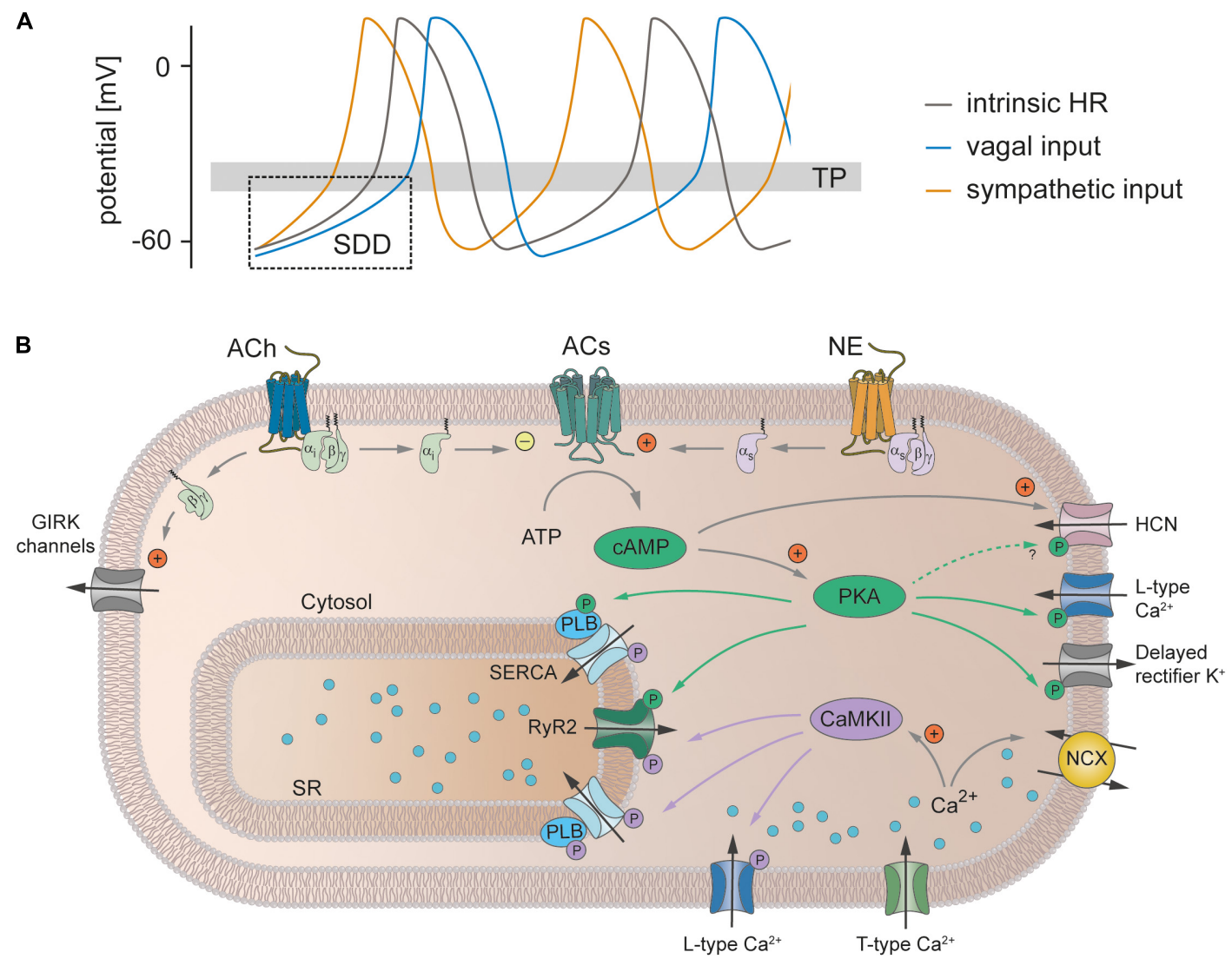

FIGURE 3 | Heart rate regulation by the autonomic nervous system. (A) SAN cell action potentials. The intrinsic action potential rate is depicted in gray. Activity of the sympathetic nervous system (orange) leads to a steeper SDD, decreases the time to reach the threshold potential (TP) for the next action potential thereby increasing action potential frequency and consequently also heart rate (positive chronotropic effect). Vagal input flattens SDD, lowers the maximum diastolic potential and thereby increases the time to reach the TP. Action potential frequency and hence HR decrease (negative chronotropic effect). (B) Signaling cascades underlying the chronotropic effect. Release of norepinephrine (NE) from sympathetic nerve terminals leads to activation of Gs protein-coupled $\beta$-receptors. Subsequent stimulation of adenylyl cyclases (ACs) increases the cytoplasmic concentration of CAMP. cAMP directly facilitates the opening of HCN channels and activates PKA, which in turn phosphorylates various proteins (indicated by green arrows and green circles), thereby increasing their activity. In addition, sympathetic activity increases the intracellular $\mathrm{Ca}^{2+}$ concentration, which increases the activity of NCX and CaMKIl. This in turn phosphorylates various target proteins (indicated by purple arrows and circles). Taken together, this steepens the SDD, increases the repolarization rate and thereby increases the action potential frequency (see text for further details). In contrast, the release of acetylcholine (ACh) during vagal activity leads to the activation of Gi protein-coupled M-receptors. ACs are inhibited by the Gi protein and thus the opposite effect of sympathetic activation unfolds. In addition, the $\beta / \gamma$-subunit activates GIRK channels that make the maximum diastolic potential more negative. Abbreviations: ACh, acetylcholine; ACs, adenylyl cyclases; ATP, adenosine triphosphate; CaMKII, $\mathrm{Ca}^{2+}$ /calmodulin-dependent protein kinase II; GIRK, G protein-coupled inwardly rectifying potassium channels; $\mathrm{HCN}$, hyperpolarization-activated cyclic nucleotide-gated cation channel; NE, norepinephrine; PKA, protein kinase A; PLB, phospholamban; RyR2, ryanodine receptor 2; SERCA, sarco-/endoplasmic reticulum $\mathrm{Ca}^{2+}$ ATPase; SR, sarcoplasmic reticulum.

mediates the regulation of HR by the ANS. This hypothesis assumes that upon activation of the sympathetic nervous system, a cAMP-dependent increase in the $\mathrm{I}_{\mathrm{f}}$ current is responsible for the acceleration of SDD that increases the firing rate of pacemaker cells and consequently the HR (Brown et al., 1979). On the other hand, a decrease in cAMP caused by activation of the parasympathetic nervous system would reduce HCN4 activity and slow down HR. However, until now this concept could not be validated in vivo and therefore remained controversially discussed. Moreover, it has been shown that, especially in the mouse SAN, the gating kinetics of HCN channels are much too slow to open and close the channels during successive action potentials, because the very high sinus rhythm and thus the firing rate of murine SAN pacemaker cells are markedly faster than the channel kinetics (Fenske et al., 2011, 2020; Hennis et al., 2021; Peters et al., 2021). As a result, HCN4-mediated current will manifest mainly as a nearly time-independent but bidirectionally flowing background current during the pacing cycle (Figure 2E), strongly arguing against a role for HCN4 in adjusting the slope of SDD and altering HR.

\section{ROLE OF HCN4 IN HR REGULATION: INSIGHTS FROM MOUSE MODELS AND HUMAN PATIENTS}

In the past 20 years, different groups have been investigating several mouse models targeting HCN4 (Table 1; Bucchi et al., 
TABLE 1 | Phenotypic manifestation of HCN4 mouse models.

\begin{tabular}{|c|c|c|c|c|}
\hline References & Model & Tissue specificity & Baseline & Stimulation \\
\hline \multicolumn{5}{|l|}{ HCN4 knockout } \\
\hline \multirow[t]{4}{*}{ Stieber et al. (2003) } & HCN4 knockout & Global & Embryonic lethality & \\
\hline & & Cardiac specific & Embryonic lethality & \\
\hline & & & $\begin{array}{l}\text { Isolated embryonic cardiomyocytes: } \\
\text { immature pacemaker potentials }\end{array}$ & cAMP: no increase in firing rate \\
\hline & & & Isolated embryonic hearts: beating rate $\downarrow$ & cAMP: no increase in beating rate \\
\hline \multirow[t]{3}{*}{ Herrmann et al. (2007) } & HCN4 knockout & Global inducible, tamoxifen & $\begin{array}{l}\text { Isolated SAN cells: large fraction of } \\
\text { quiescent cells with hyperpolarized } \\
\text { membrane potential }\end{array}$ & Iso: quiescent SAN cells rescued \\
\hline & & & Isolated hearts: sinus pauses & \\
\hline & & & $\begin{array}{l}\text { In vivo adult mice: sinus pauses, HR } \\
\text { unchanged }\end{array}$ & $\begin{array}{l}\text { Iso: preserved max. HR, preserved } \\
\text { chronotropic effect Carbachol or } \\
\text { CCPA: HR } \downarrow\end{array}$ \\
\hline \multirow[t]{2}{*}{ Hoesl et al. (2008) } & HCN4 knockout & $\begin{array}{l}\text { Conduction system specific } \\
\text { inducible, tamoxifen }\end{array}$ & $\begin{array}{l}\text { Isolated SAN cells: large fraction of } \\
\text { quiescent cells with hyperpolarized } \\
\text { membrane potential }\end{array}$ & \\
\hline & & & $\begin{array}{l}\text { In vivo adult mice: sinus pauses, HR } \\
\text { unchanged }\end{array}$ & $\begin{array}{l}\text { Iso: preserved max. HR, preserved } \\
\text { chronotropic effect Carbachol or } \\
\text { CCPA: HR } \downarrow\end{array}$ \\
\hline \multirow[t]{2}{*}{ Baruscotti et al. (2011) } & HCN4 knockout & $\begin{array}{l}\text { Cardiac specific inducible, } \\
\text { tamoxifen }\end{array}$ & Isolated SAN cells: firing rate $\downarrow$ & $\begin{array}{l}\text { Iso: max. firing rate } \downarrow \text {, preserved } \\
\text { chronotropic action }\end{array}$ \\
\hline & & & $\begin{array}{l}\text { In vivo adult mice: bradycardia, AV-blocks, } \\
\text { sinus arrest }\end{array}$ & $\begin{array}{l}\text { Iso: max. HR } \downarrow \text {, preserved } \\
\text { chronotropic effect }\end{array}$ \\
\hline \multirow[t]{2}{*}{ Mesirca et al. (2014) } & $\begin{array}{l}\text { hHCN4-AYA } \\
\text { dominant-negative }\end{array}$ & $\begin{array}{l}\text { Cardiac specific inducible, } \\
\text { dox-withdrawal }\end{array}$ & Isolated SAN cells: firing rate $\downarrow$ & $\begin{array}{l}\text { Iso: max. firing rate } \downarrow \text {, preserved } \\
\text { chronotropic action }\end{array}$ \\
\hline & & & $\begin{array}{l}\text { In vivo adult mice: bradycardia, sinus } \\
\text { pauses, AV blocks, ventricular tachycardia }\end{array}$ & $\begin{array}{l}\text { Iso: max. HR } \downarrow \text {, preserved } \\
\text { chronotropic effect }\end{array}$ \\
\hline
\end{tabular}

$\begin{array}{lll}\text { Kozasa et al. (2018) } & \text { HCN4 } & \text { Global HZ without dox } \\ & \text { overexpression } & \end{array}$

Embryonic lethality (homozygous with and w/o dox)

Isolated SAN cells: firing rate unchanged

In vivo adult mice: HR unchanged, HRV $\downarrow$

HCN4 knockdown

Alig et al. (2009) $\begin{array}{ll}\text { hHCN4-573X } \\ \text { transgenic }\end{array}$

Fenske et al. (2020)
HCN4FEA Y527F, R669E, T670A knock-in

\section{cAMP-insensitive HCN4 channels} $\begin{array}{ll}\text { Harzheim et al. (2008) } & \text { HCN4 R669Q } \\ & \text { knock-in }\end{array}$
Global inducible, $\mathrm{HZ}$ with dox

Global
Isolated SAN cells: firing rate $\downarrow$

In vivo adult mice: bradycardia, sinus arrhythmia, HRV $\uparrow$

Embryonic lethality (homozygous)

Isolated embryonic cardiomyocytes: firing rate $\downarrow$

Isolated embryonic hearts: beating rate $\downarrow$ Isolated adult hearts $(\mathrm{HZ})$ : unchanged beating rate

In vivo adult mice $(\mathrm{HZ})$ : unchanged $\mathrm{HR}$

Cardiac specific inducible, dox-withdrawal intermittent beating cells, beating rate $\downarrow$

In vivo adult mice: bradycardia, HR regulation preserved

Isolated SAN cells: cells alternate between firing and non-firing mode

Isolated hearts: beating rate $\downarrow$

In vivo adult mice: bradycardia, sinus dysrhythmia, preserved chronotropic effect

ACh: beating rate reduction $\downarrow$ Iso: preserved max. HR VNS: beating rate reduction $\downarrow$

ACh: beating rate reduction $\uparrow$

Iso: preserved max. HR VNS: beating rate reduction $\uparrow$

Iso: absence of chronotropic effect

Iso: rescues quiescent and interm beating cells, max. beating rate $\downarrow$, preserved chronotropic action

Iso: time spent in non-firing mode $\downarrow$, preserved chronotropic action

VNS: sinus pauses

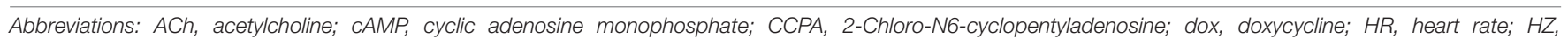

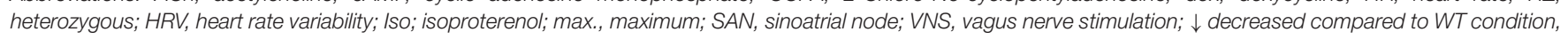
$\uparrow$ increased compared to WT condition. 
2012; Herrmann et al., 2012). The findings of these studies led to conflicting hypotheses about the role of HCN4 CDR in HR regulation. Stieber et al. (2003) created HCN4 knockout mice by generating a non-functional construct lacking the pore, which prevents translation of a functional protein and thereby results in complete absence of HCN4. Loss of HCN4 in these mice led to embryonic lethality due to a strongly diminished $\mathrm{I}_{\mathrm{f}}$ during cardiac development. By studying embryonic $\mathrm{HCN} 4^{-/-}$ hearts and isolated cardiomyocytes the authors found that HR was markedly reduced by about $40 \%$ and that $\mathrm{HR}$ and action potential firing rate could not be accelerated by CAMP. Surprisingly, a further study revealed that mice carrying only a point mutation in the CNBD of $\mathrm{HCN} 4$ also die during embryonic development (Harzheim et al., 2008). A single amino acid exchange (R669Q), which results in abolished CDR but otherwise unaltered channel function, caused embryonic lethality. This indicates that binding of cAMP to HCN4 is a general pre-requisite for the physiological function of the channel. Furthermore, the authors reported significantly reduced HRs and absent responses to catecholaminergic stimulation in embryonic hearts. Taken together, these studies suggest an important role of $\mathrm{HCN} 4 \mathrm{CDR}$ in mediating the chronotropic effect, although insights are restricted to findings from embryonic states in which the SAN and cardiac conduction system are not yet fully developed.

In order to overcome the limitations caused by embryonic lethality, Baruscotti et al. (2011) generated a mouse model in which cardiac-specific knockout of HCN4 was achieved in a temporally controlled manner, thereby enabling investigation of adult mice lacking HCN4 channels in the heart. In these mice, loss of HCN4 led to progressively developing bradycardia and AV block, which finally resulted in sinus arrest and cardiac death. However, HR response to betaadrenergic stimulation was not affected by the tamoxifen-induced knockout of HCN4. In 2014, the findings were supported by a further study investigating heart-specific silencing of $\mathrm{I}_{\mathrm{f}}$ by transgenic expression of a dominant-negative, non-conductive HCN4-channel subunit (hHCN4-AYA) in adult mice (Mesirca et al., 2014). The animals showed significant SAN dysfunction reflected by frequent sinus pauses and reduced $\mathrm{HR}$, while sympathetic regulation of $\mathrm{HR}$ was unaltered. Unexpectedly, another study reported that diminished $\mathrm{I}_{\mathrm{f}}$ due to a comparable approach of tamoxifen-induced, global knockout of HCN4 gave rise to cardiac arrhythmia in the form of recurrent sinus pauses, whereas the mice showed no signs of bradycardia under baseline conditions (Herrmann et al., 2007). However, HR acceleration induced by exercise or injection of isoproterenol was normal, which demonstrates preserved beta-adrenergic HR regulation also in these animals. Significantly lower HRs were only detected after application of carbachol or CCPA, an A1 adenosine receptor agonist, indicating overshooting parasympathetic responses of the SAN in the absence of HCN4. On the single cell level, knockout of HCN4 resulted in a quiescent phenotype of pacemaker cells characterized by a hyperpolarized maximum diastolic potential that was reversible upon application of isoproterenol. A further study by the same group, in which HCN4 was deleted explicitly in pacemaker cells of the sinoatrial and atrioventricular node, confirmed these results (Hoesl et al., 2008). Kozasa et al. (2018) investigated the contribution of HCN4 to the autonomic regulation of the SAN by transgenic overexpression or knockdown of HCN4 channels in mice. Surprisingly, overexpression of HCN4 did not induce tachycardia, but reduced HR variability, possibly due to excessively attenuated ANS input. This was evident in HR histograms derived from $24 \mathrm{~h}$ telemetric electrocardiogram (ECG) recordings. Histograms from HCN4-overexpressing mice were characterized by a unimodal distribution with a single peak in the intermediate frequency range and a symmetrically reduced total HR range. In contrast, HRs in WT histograms were bimodally distributed with a considerably broader frequency range. Furthermore, conditional knockdown of HCN4 induced pronounced bradycardia and gave rise to sinus arrhythmia and enhanced parasympathetic responses to cervical vagus nerve stimulation. Following injection of isoproterenol, bradycardia induced by cervical vagus nerve stimulation was attenuated in HCN4-overexpressing mice. Remarkably, neither overexpression nor knockdown of HCN4 altered the HR response of the SAN to beta-adrenergic stimulation. Taken together, this study suggests that HCN4 is responsible for stabilizing the spontaneous firing of the SAN mainly by attenuating the parasympathetic response. Thus, HCN4 channels protect the SAN network during parasympathetic regulation while the cAMP-dependent activation of HCN4 seems to enhance this protective effect. A few years ago, further insight into $\mathrm{CDR}$ of $\mathrm{HCN} 4$ was provided by Baruscotti et al. (2017), who identified the first gain-offunction mutation in $\mathrm{HCN} 4$ in a patient with inappropriate sinus tachycardia. The R524Q mutation is located in the C-linker, a region that couples cAMP binding to channel activation. Heterologous expression of R524Q mutant HCN4 channels revealed increased sensitivity to CAMP, and rat neonatal cardiomyocytes transfected with the mutant channel construct displayed enhanced spontaneous beating rates. Accordingly, the symptoms in human patients included prolonged periods of sinus tachycardia and frequent palpitations at rest and during exercise. This suggests that overactive CDR of HCN4 may lead to excessive responses of the SAN network to sympathetic stimulation, but unfortunately these observations were not further investigated mechanistically as no mouse model with this particular mutation is available to date.

To study the role of HCN4 CDR more specifically, a transgenic mouse model was generated by Alig et al. (2009). The mice were created with a mutation (573X) that was initially identified in a human patient with sinus node dysfunction (Schulze-Bahr et al., 2003). The structure of HCN4 is highly conserved between different species, including mice and humans, which in principle justifies the use of the mouse as a model organism for the study of $\mathrm{HCN} 4 \mathrm{CDR}$. The mutation results in a truncation of the C-terminus of HCN4 that includes the CNBD and thereby causes cAMP insensitivity of the channel. Transgenic, cardiacspecific overexpression of the mutant construct (hHCN4-573X) in adult mice suppressed cAMP sensitivity of HCN4 in a dominant-negative manner. The cardiac phenotype of these mice was characterized by a marked reduction in $\mathrm{HR}$ at 
rest and during exercise, while the relative range of $\mathrm{HR}$ regulation was unchanged. On the single cell level, the mutation caused a heterogeneous phenotype with isolated pacemaker cells being arrhythmic, alternating between spontaneous firing and subthreshold membrane potential oscillations, or completely lacking electrical automaticity. These observations widely match with the symptoms of the human patient, which include bradycardia and chronotropic incompetence due to idiopathic sinus node dysfunction (Schulze-Bahr et al., 2003). The findings provide important insights into the physiological role of HCN4 in the SAN and further support the theory that HR regulation by the ANS is not mediated by CDR of HCN4. However, the mutation in this model causes a C-terminal truncation involving a total of 630 amino acids. Since the sequence of the CNBD comprises only 119 amino acids (Ludwig et al., 1999), it is obvious that the truncation eliminates not only the CNBD but also many other structural domains, including potential phosphorylation sites and binding domains for various modulators in addition to cAMP. Therefore, the cardiac phenotype of the mice cannot be directly attributed to absent CDR of HCN4.

To particularly investigate the physiological implication of HCN4 CDR, our group created a knock-in mouse model with two amino acid exchanges in the CNBD and one in the C-linker, which result in loss of CDR of the channel while embryonic lethality is prevented (HCN4FEA mouse line) (Fenske et al., 2020). These mice displayed pronounced bradycardia, whereas the entire range of $\mathrm{HR}$ regulation was preserved. The findings strongly support the theory that, in contrast to previous assumptions, $\mathrm{CDR}$ of $\mathrm{HCN} 4$ is not required for the classical chronotropic effect. In addition, several other human HCN4 channelopathies have been reported that result in loss of HCN4 function (Verkerk and Wilders, 2015). The mutations lead to diverse cardiac syndromes, the majority of which include bradycardia. However, in some of these channelopathies HR modulation by beta-adrenergic stimulation is preserved. Unfortunately, a straight forward interpretation of these cardiac phenotypes on HCN4 function is compromised by the fact that all patients identified so far display heterozygous mutations and thus also express an unmodified copy of HCN4.

In summary, evidence is growing that the role of $\mathrm{HCN} 4$ in the SAN is different to the originally postulated HR regulation by the ANS and that the classical chronotropic effect is mainly carried out by pacemaker mechanisms other than HCN4. Instead, it seems more likely that HCN4 is involved in setting the intrinsic HR (i.e., HR in the absence of autonomic regulation) and, in particular, in determining the lower part of the HR range. Furthermore, the channel appears to exert a protective effect on the SAN network especially during parasympathetic activity, thereby suppressing bradycardia. In contrast, HR modulation by the ANS is still possible in the absence of HCN4. It remains unclear why a minor part of the mouse studies did not report occurrence of bradycardia after deletion of HCN4 (Herrmann et al., 2007; Hoesl et al., 2008). Possible explanations might include that some HCN4 channels remain present after application of tamoxifen due to insufficient Cre activation. Furthermore, differences in the genetic background of the (sub-) strains of mice used in the studies could also contribute to these functional discrepancies (Bucchi et al., 2012).

\section{NON-FIRING PACEMAKER CELLS IN THE SINOATRIAL NODE}

Several mouse studies have shown that inhibition of various components involved in cardiac automaticity gives rise to the presence of quiescent states in isolated pacemaker cells. For example, pacemaker cells isolated from atrial-specific NCX knockout mice are completely quiescent, which leads to intermittent burst pacemaker activity of the SAN network. This is characterized by frequent, short pauses of a few seconds, reminiscent of human sinus node dysfunction and "tachy-brady" syndrome (Torrente et al., 2015). Furthermore, as outlined above, knockout of HCN4 as well as truncation of the HCN4 C-terminus cause quiescent phenotypes of isolated SAN pacemaker cells (Herrmann et al., 2007; Alig et al., 2009). However, it has only recently been discovered that non-firing pacemaker cells are also present and functionally relevant in vivo in the intact SAN of WT animals, especially during HR regulation by the ANS (Fenske et al., 2020). These findings reported by our group revealed that $\mathrm{HCN} 4$ channels indeed play an important role in HR regulation, but that this is based on a completely different mechanism than originally postulated. In this study, we found that isolated pacemaker cells expressing cAMP-insensitive HCN4FEA channels, but also WT cells, can spontaneously switch into a non-firing mode that is characterized by a hyperpolarized membrane potential and lasts for up to $1 \mathrm{~min}$. Non-firing was more pronounced in HCN4FEA cells but could also reliably be induced in WT cells by application of carbachol or TATTRIP8 $b_{\text {nano, }}$ a synthetic peptide that prevents CDR in HCN channels (Saponaro et al., 2018). Strikingly, ex vivo confocal calcium imaging of intact SAN preparations revealed that nonfiring pacemaker cells are also present in the intact SAN and significantly modify SAN network activity. This is in line with findings from another recent study which reported presence of markedly heterogeneous calcium signals in adjacent cells within the SAN network (Bychkov et al., 2020), indicating that not all pacemaker cells in the SAN generate full-scale action potentials at a given time.

What is the exact functional relevance of non-firing pacemaker cells in the SAN? From our experimental findings we derived the hypothesis that a tonic electrical interaction via gap junctions takes place between cells in the non-firing mode and neighboring cells in the firing mode. During nonfiring, pacemaker cells are significantly more hyperpolarized than firing cells for a period of up to $1 \mathrm{~min}$. Through tonic interaction, these cells act as "brakes" in the network of the SAN and inhibit the activity of neighboring pacemaker cells in the firing mode. This interaction lowers the maximum diastolic potential and slows down the SDD of the firing cells, and thus slows down basal HR. In addition, tonic inhibition seems to increase during vagal activity and decrease during betaadrenergic stimulation, probably because more cells switch to the non-firing mode or firing mode, respectively. This process 
is very important for setting the intrinsic $H R$ and stabilizing SAN network activity, but not for changing HR per se. However, because the mechanism is dependent on cAMP and CDR of HCN4, it also contributes substantially to the regulation of SAN network activity by the ANS. According to this new hypothesis, CDR of HCN4 determines the number of pacemaker cells in the non-firing mode and is essential to ensure a safe and stable transition between different HRs during sympathetic and/or vagal activity, while it appears to be particularly important in fine-tuning the HR-lowering effect of the parasympathetic nervous system. During high vagal activity, HCN4 effectively counteracts hyperpolarizing changes in the membrane potential. This effect is due to the well-known properties of HCN channels to dampen inhibitory and excitatory stimuli, thereby stabilizing the membrane potential (Robinson and Siegelbaum, 2003; Nolan et al., 2004; Narayanan and Johnston, 2008; Biel et al., 2009; Wahl-Schott et al., 2014). Via CDR of HCN4, the extent of this antagonizing effect, i.e., the gain of negative feedback, can be adjusted according to the situation, which effectively stabilizes HR. Conversely, in the absence of CDR, responses of the SAN to ANS activity are exaggerated which results in extreme HR fluctuations, sinus dysrhythmia and instability of mean HR [for review see also: (Hennis et al., 2021)].

It is known that, in general, inhibitory elements increase the stability of electrically active networks. For example, inhibitory interneurons in the brain provide a mechanism to balance the activity of otherwise unstable neuronal networks (Markram et al., 2004; Sadeh and Clopath, 2021). Our work shows that inhibitory control of excitability is also essential in the SAN to ensure a stable function of the pacemaker process and to protect the SAN network during ANS activity. Taken together, CDR counteracts parasympathetic override, inappropriate HR decreases and the occurrence of bradycardia, which is completely different to the originally postulated HR regulation by the ANS and the classical chronotropic effect (Kozasa et al., 2018; Fenske et al., 2020).

\section{ALTERNATIVE CONCEPTS FOR CLASSICAL CHRONOTROPIC RESPONSE}

It is becoming more and more accepted that the role of HCN4 in the SAN is to set the intrinsic HR and stabilize the SAN network during input from the ANS. Therefore, the question arises as to which molecular component(s) of SAN pacemaking actually mediate(s) the chronotropic effect. It is well known that betaadrenergic signaling in the SAN activates the stimulating adenylyl cyclase-cAMP-protein kinase A (PKA) cascade (Figure 3B; Behar et al., 2016). Besides direct effects, e.g., on HCN4, cAMP binds to and activates PKA, which in turn phosphorylates and activates numerous target proteins in the cell, many of them involved in pacemaker activity (MacDonald et al., 2020). These targets include L-type $\mathrm{Ca}^{2+}$ channels (van der Heyden et al., 2005), phospholamban (Vinogradova et al., 2010), RyR (Shan et al., 2010), delayed rectifier potassium channels (Lei et al., 2000), $\mathrm{Na}^{+} / \mathrm{K}^{+}$-ATPase (Gao et al., 1994), and HCN channels (Liao et al., 2010). In addition, there is also evidence that sympathetic stimulation activates $\mathrm{Ca}^{2+} /$ calmodulin-dependent protein kinase II (CaMKII) (Wu et al., 2009; Grimm and Brown, 2010; Wu and Anderson, 2014), which shares a number of downstream targets with PKA, i.e., L-type $\mathrm{Ca}^{2+}$ channels (Vinogradova et al., 2000), phospholamban and RyR2 (Li et al., 2016). Accordingly, voltagegated $\mathrm{Ca}^{2+}$ channels are a component of the membrane clock different to HCN4 that could possibly mediate the chronotropic effect. While a potential isoproterenol-induced effect on $\mathrm{I}_{\mathrm{Ca}}, \mathrm{T}$ in the SAN is not completely resolved (Hagiwara et al., 1988; Li et al., 2012), $\mathrm{I}_{\mathrm{Ca}, \mathrm{L}}$ is enhanced following PKA-dependent (van der Heyden et al., 2005; Mangoni and Nargeot, 2008) and CaMKII-dependent phosphorylation (Dzhura et al., 2000; Vinogradova et al., 2000; Mangoni and Nargeot, 2008). In line with this, knockout of L-type $\mathrm{Ca}_{\mathrm{V}} 1.3$ channels in mice slowed the firing rate of isolated SAN pacemaker cells and reduced the slopes of both the early and late phase of SDD (Mangoni et al., 2003; Baudot et al., 2020). However, it has been indicated that $\mathrm{I}_{\mathrm{Ca}, \mathrm{L}}$ augmentation alone is not sufficient to achieve the normal increase in action potential firing rate upon beta-adrenergic stimulation (Vinogradova et al., 2002; Lakatta et al., 2010).

It is therefore possible that modulation of the calcium clock could play a key role in HR regulation by the ANS (Figure 3B). In this concept, activation of PKA and/or CaMKII would increase LCRs from the SR due to (A) accelerated $\mathrm{Ca}^{2+}$ reuptake into the SR following either direct CaMKII-dependent stimulation of SERCA (Narayanan and Xu, 1997) or disinhibition of SERCA by PKA/CaMKII-dependent phosphorylation of phospholamban (Vinogradova et al., 2010; Li et al., 2016) and/or (B) increased release of $\mathrm{Ca}^{2+}$ from the SR due to phosphorylation of RyR2 by PKA and/or CaMKII (Vinogradova et al., 2002; Bers, 2006; Shan et al., 2010). This would lead to enhanced LCRs that also occur earlier in the pacemaker cycle. Since LCRs activate NCX by elevating intracellular $\mathrm{Ca}^{2+}$, the consequences would include an increase in depolarizing $\mathrm{I}_{\mathrm{NCX}}$ current with an onset earlier in SDD, thereby accelerating SDD and reducing the pacemaker cycle length, i.e., increasing the firing frequency (Bogdanov et al., 2006; Maltsev and Lakatta, 2009; Lakatta et al., 2010).

There are several aspects that argue in favor of this theory. First, Förster resonance energy transfer (FRET) experiments showed that PKA activity in isolated SAN pacemaker cells is tightly linked to action potential firing rate in response to either adrenergic or cholinergic stimulation (Behar et al., 2016). In addition, beta-adrenergic stimulation of PKA activity enhances LCRs, whereas inhibition of PKA abolishes LCRs and significantly interferes with cellular automaticity (Vinogradova et al., 2006). Furthermore, it has been shown that also CaMKII activity is essential for stimulating LCRs to cause a physiological HR increase (Wu et al., 2009; Swaminathan et al., 2011). This indicates that (possibly common) downstream targets of PKA and CaMKII, which are attributable to the calcium clock, could be responsible for mediating the chronotropic response.

Second, there is evidence that the rate of refilling the SR $\mathrm{Ca}^{2+}$ storage during diastole has a direct influence on the chronotropic state of the SAN. It has been demonstrated that direct pharmacological inhibition of SERCA prolongs the spontaneous cycle length of isolated SAN pacemaker cells, whereas changes in PKA/CaMKII-dependent phospholamban phosphorylation, 
which lead to successive disinhibition of SERCA, are paralleled by a reduction of the LCR period and pacemaker cycle length (Vinogradova et al., 2010; Li et al., 2016).

Third, it has been indicated that modulation of RyR2 function is indispensable for physiological HR adaption (Vinogradova et al., 2006; Eschenhagen, 2010; Shan et al., 2010). Accordingly, when RyRs in SAN pacemaker cells are blocked by ryanodine, or when phosphorylation of RyR2 by PKA is genetically inhibited, augmentation of $\mathrm{I}_{\mathrm{NCX}}$, acceleration of SDD and increase in firing frequency following beta-adrenergic stimulation are diminished (Rigg et al., 2000; Lakatta et al., 2010; Shan et al., 2010).

Fourth, there is evidence that the $\mathrm{Na}^{+}-\mathrm{Ca}^{2+}$ exchanger (NCX) plays a fundamental role in SAN automaticity and contributes significantly to the positive chronotropic modulation of the SAN (Zhou and Lipsius, 1993; Bogdanov et al., 2001, 2006). NCX knockout mice and numerical $I_{N C X}$ and $\mathrm{Ca}^{2+}$ dynamics model simulations revealed decreased or completely abolished responsiveness to isoproterenol stimulation (Bogdanov et al., 2006; Gao et al., 2013; Maltsev et al., 2013), suggesting that $\mathrm{I}_{\mathrm{NCX}}$ is a crucial contributor to the fight-or-flight response in the SAN.

In conclusion, it has become clear that $\mathrm{HCN} 4$ is not required for mediating the classical chronotropic effect, but rather contributes to determining the intrinsic HR and protecting the stability of the SAN network during ANS activity. Instead, it is more likely that one or several components of the calcium clock are the key mediators of $\mathrm{HR}$ regulation by the ANS.

\section{REFERENCES}

Alig, J., Marger, L., Mesirca, P., Ehmke, H., Mangoni, M. E., and Isbrandt, D. (2009). Control of heart rate by cAMP sensitivity of HCN channels. Proc. Natl. Acad. Sci. U.S.A. 106, 12189-12194. doi: 10.1073/pnas.0810332106

Baartscheer, A., Schumacher, C. A., Coronel, R., and Fiolet, J. W. (2011). The driving force of the $\mathrm{Na} / \mathrm{Ca}$-exchanger during metabolic inhibition. Front. Physiol. 2:10. doi: 10.3389/fphys.2011.00010

Baruscotti, M., Bucchi, A., Milanesi, R., Paina, M., Barbuti, A., Gnecchi-Ruscone, T., et al. (2017). A gain-of-function mutation in the cardiac pacemaker HCN4 channel increasing cAMP sensitivity is associated with familial Inappropriate Sinus Tachycardia. Eur. Heart J. 38, 280-288. doi: 10.1093/eurheartj/ehv582

Baruscotti, M., Bucchi, A., Viscomi, C., Mandelli, G., Consalez, G., GnecchiRusconi, T., et al. (2011). Deep bradycardia and heart block caused by inducible cardiac-specific knockout of the pacemaker channel gene Hcn4. Proc. Natl. Acad. Sci. U.S.A. 108, 1705-1710. doi: 10.1073/pnas.10101 22108

Baudot, M., Torre, E., Bidaud, I., Louradour, J., Torrente, A. G., Fossier, L., et al. (2020). Concomitant genetic ablation of L-type Cav1.3 (alpha1D) and T-type Cav3.1 (alpha1G) Ca(2+) channels disrupts heart automaticity. Sci. Rep. 10:18906. doi: 10.1038/s41598-020-76049-7

Behar, J., Ganesan, A., Zhang, J., and Yaniv, Y. (2016). The autonomic nervous system regulates the heart rate through cAMP-PKA dependent and independent coupled-clock pacemaker cell mechanisms. Front. Physiol. 7:419. doi: 10.3389/fphys.2016.00419

Bers, D. M. (2006). Cardiac ryanodine receptor phosphorylation: target sites and functional consequences. Biochem. J. 396:e1. doi: 10.1042/BJ20060377

Bers, D. M., Christensen, D. M., and Nguyen, T. X. (1988). Can Ca entry via Na-Ca exchange directly activate cardiac muscle contraction? J. Mol. Cell. Cardiol. 20, 405-414. doi: 10.1016/s0022-2828(88)80132-9

Biel, M., Wahl-Schott, C., Michalakis, S., and Zong, X. (2009). Hyperpolarizationactivated cation channels: from genes to function. Physiol. Rev. 89, 847-885. doi: 10.1152/physrev.00029.2008
However, since there are numerous redundant processes involved in this cascade, with some of them possibly representing backup mechanisms to ensure proper chronotropic responses in the case of dysfunction of other components, the major contributor to HR adaption in the SAN remains yet to be identified.

\section{AUTHOR CONTRIBUTIONS}

$\mathrm{KH}, \mathrm{SF}$, and CW-S wrote the manuscript. SF and RR composed the figures. $\mathrm{RR}, \mathrm{CP}$, and $\mathrm{MB}$ revised the manuscript. All authors carefully revised the literature and approved the final version of the manuscript.

\section{FUNDING}

Open Access funding enabled and organized by Projekt DEAL. This work was supported by the German Research Foundation [FE 1929/1-1, WA 2597/3-1, BI 484/5-1, and TRR152].

\section{ACKNOWLEDGMENTS}

We thank Dainius Pauza and Audrys Pauza for their help in establishing the preparation of gelatine-inflated hearts to visualize the anatomy of the sinoatrial node region.

Bogdanov, K. Y., Maltsev, V. A., Vinogradova, T. M., Lyashkov, A. E., Spurgeon, H. A., Stern, M. D., et al. (2006). Membrane potential fluctuations resulting from submembrane $\mathrm{Ca} 2+$ releases in rabbit sinoatrial nodal cells impart an exponential phase to the late diastolic depolarization that controls their chronotropic state. Circ. Res. 99, 979-987. doi: 10.1161/01.RES.0000247933. $66532.0 \mathrm{~b}$

Bogdanov, K. Y., Vinogradova, T. M., and Lakatta, E. G. (2001). Sinoatrial nodal cell ryanodine receptor and $\mathrm{Na}(+)-\mathrm{Ca}(2+)$ exchanger: molecular partners in pacemaker regulation. Circ. Res. 88, 1254-1258. doi: 10.1161/hh1201. 092095

Brown, H. F., Difrancesco, D., and Noble, S. J. (1979). How does adrenaline accelerate the heart? Nature 280, 235-236. doi: 10.1038/280235a0

Bucchi, A., Barbuti, A., Difrancesco, D., and Baruscotti, M. (2012). Funny current and cardiac rhythm: insights from HCN knockout and transgenic mouse models. Front. Physiol. 3:240. doi: 10.3389/fphys.2012.00240

Bychkov, R., Juhaszova, M., Tsutsui, K., Coletta, C., Stern, M. D., Maltsev, V. A., et al. (2020). Synchronized cardiac impulses emerge from heterogeneous local calcium signals within and among cells of pacemaker tissue. JACC Clin. Electrophysiol. 6, 907-931. doi: 10.1016/j.jacep.2020.06.022

Camelliti, P., Green, C. R., Legrice, I., and Kohl, P. (2004). Fibroblast network in rabbit sinoatrial node: structural and functional identification of homogeneous and heterogeneous cell coupling. Circ. Res. 94, 828-835. doi: 10.1161/01.RES. 0000122382.19400 .14

Chandler, N. J., Greener, I. D., Tellez, J. O., Inada, S., Musa, H., Molenaar, P., et al. (2009). Molecular architecture of the human sinus node: insights into the function of the cardiac pacemaker. Circulation 119, 1562-1575. doi: 10.1161/ CIRCULATIONAHA.108.804369

Cingolani, E., Goldhaber, J. I., and Marban, E. (2018). Next-generation pacemakers: from small devices to biological pacemakers. Nat. Rev. Cardiol. 15, 139-150. doi: 10.1038/nrcardio.2017.165

Denyer, J. C., and Brown, H. F. (1990). Pacemaking in rabbit isolated sino-atrial node cells during Cs+ block of the hyperpolarization-activated current if. J. Physiol. 429, 401-409. doi: 10.1113/jphysiol.1990.sp018264 
DiFrancesco, D. (1993). Pacemaker mechanisms in cardiac tissue. Annu. Rev. Physiol. 55, 455-472. doi: 10.1146/annurev.ph.55.030193.002323

DiFrancesco, D., Ferroni, A., Mazzanti, M., and Tromba, C. (1986). Properties of the hyperpolarizing-activated current (if) in cells isolated from the rabbit sino-atrial node. J. Physiol. 377, 61-88. doi: 10.1113/jphysiol.1986.sp01 6177

DiFrancesco, D., and Tortora, P. (1991). Direct activation of cardiac pacemaker channels by intracellular cyclic AMP. Nature 351, 145-147. doi: 10.1038/ $351145 \mathrm{a} 0$

Dobrev, D. (2009). Ion channel portrait of the human sinus node: useful for a better understanding of sinus node function and dysfunction in humans? Circulation 119, 1556-1558. doi: 10.1161/CIRCULATIONAHA.108.836866

Dzhura, I., Wu, Y., Colbran, R. J., Balser, J. R., and Anderson, M. E. (2000). Calmodulin kinase determines calcium-dependent facilitation of L-type calcium channels. Nat. Cell Biol. 2, 173-177. doi: 10.1038/35004052

Eschenhagen, T. (2010). Is ryanodine receptor phosphorylation key to the fight or flight response and heart failure? J. Clin. Invest. 120, 4197-4203. doi: 10.1172/ JCI45251

Fedorov, V. V., Glukhov, A. V., Chang, R., Kostecki, G., Aferol, H., Hucker, W. J., et al. (2010). Optical mapping of the isolated coronary-perfused human sinus node. J. Am. Coll. Cardiol. 56, 1386-1394. doi: 10.1016/j.jacc.2010.03.098

Fenske, S., Hennis, K., Rotzer, R. D., Brox, V. F., Becirovic, E., Scharr, A., et al. (2020). cAMP-dependent regulation of HCN4 controls the tonic entrainment process in sinoatrial node pacemaker cells. Nat. Commun. 11:5555. doi: 10.1038/ s41467-020-19304-9

Fenske, S., Krause, S. C., Hassan, S. I., Becirovic, E., Auer, F., Bernard, R., et al. (2013). Sick sinus syndrome in HCN1-deficient mice. Circulation 128, 25852594. doi: 10.1161/CIRCULATIONAHA.113.003712

Fenske, S., Mader, R., Scharr, A., Paparizos, C., Cao-Ehlker, X., Michalakis, S., et al. (2011). HCN3 contributes to the ventricular action potential waveform in the murine heart. Circ. Res. 109, 1015-1023. doi: 10.1161/CIRCRESAHA.111. 246173

Gao, J., Cohen, I. S., Mathias, R. T., and Baldo, G. J. (1994). Regulation of the betastimulation of the $\mathrm{Na}(+)-\mathrm{K}+$ pump current in guinea-pig ventricular myocytes by a cAMP-dependent PKA pathway. J. Physiol. 477(Pt 3), 373-380. doi: 10. 1113/jphysiol.1994.sp020199

Gao, Z., Rasmussen, T. P., Li, Y., Kutschke, W., Koval, O. M., Wu, Y., et al. (2013). Genetic inhibition of $\mathrm{Na}+-\mathrm{Ca} 2+$ exchanger current disables fight or flight sinoatrial node activity without affecting resting heart rate. Circ. Res. 112, 309-317. doi: 10.1161/CIRCRESAHA.111.300193

Grimm, M., and Brown, J. H. (2010). Beta-adrenergic receptor signaling in the heart: role of CaMKII. J. Mol. Cell. Cardiol. 48, 322-330. doi: 10.1016/j.yjmcc. 2009.10.016

Hagiwara, N., Irisawa, H., and Kameyama, M. (1988). Contribution of two types of calcium currents to the pacemaker potentials of rabbit sino-atrial node cells. J. Physiol. 395, 233-253. doi: 10.1113/jphysiol.1988.sp016916

Harzheim, D., Pfeiffer, K. H., Fabritz, L., Kremmer, E., Buch, T., Waisman, A., et al. (2008). Cardiac pacemaker function of HCN4 channels in mice is confined to embryonic development and requires cyclic AMP. EMBO J. 27, 692-703. doi: $10.1038 /$ emboj.2008.3

Hennis, K., Biel, M., Wahl-Schott, C., and Fenske, S. (2021). Beyond pacemaking: HCN channels in sinoatrial node function. Prog. Biophys. Mol. Biol. doi: 10. 1016/j.pbiomolbio.2021.03.004 [Epub ahead of print].

Herrmann, S., Hofmann, F., Stieber, J., and Ludwig, A. (2012). HCN channels in the heart: lessons from mouse mutants. Br. J. Pharmacol. 166, 501-509. doi: 10.1111/j.1476-5381.2011.01798.x

Herrmann, S., Layh, B., and Ludwig, A. (2011). Novel insights into the distribution of cardiac HCN channels: an expression study in the mouse heart. J. Mol. Cell. Cardiol. 51, 997-1006. doi: 10.1016/j.yjmcc.2011.09.005

Herrmann, S., Stieber, J., Stockl, G., Hofmann, F., and Ludwig, A. (2007). HCN4 provides a 'depolarization reserve' and is not required for heart rate acceleration in mice. EMBO J. 26, 4423-4432. doi: 10.1038/sj.emboj.7601868

Ho, S. Y., and Sanchez-Quintana, D. (2016). Anatomy and pathology of the sinus node. J. Interv. Card. Electrophysiol. 46, 3-8. doi: 10.1007/s10840-0150049-6

Hoesl, E., Stieber, J., Herrmann, S., Feil, S., Tybl, E., Hofmann, F., et al. (2008). Tamoxifen-inducible gene deletion in the cardiac conduction system. J. Mol. Cell. Cardiol. 45, 62-69. doi: 10.1016/j.yjmcc.2008.04.008
Hulsmans, M., Clauss, S., Xiao, L., Aguirre, A. D., King, K. R., Hanley, A., et al. (2017). Macrophages facilitate electrical conduction in the heart. Cell 169, 510-522.e20. doi: 10.1016/j.cell.2017.03.050

Irisawa, H., Brown, H. F., and Giles, W. (1993). Cardiac pacemaking in the sinoatrial node. Physiol. Rev. 73, 197-227. doi: 10.1152/physrev.1993.73. 1.197

Kalyanasundaram, A., Li, N., Hansen, B. J., Zhao, J., and Fedorov, V. V. (2019). Canine and human sinoatrial node: differences and similarities in the structure, function, molecular profiles, and arrhythmia. J. Vet. Cardiol. 22, 2-19. doi: 10.1016/j.jvc.2018.10.004

Kharche, S., Yu, J., Lei, M., and Zhang, H. (2011). A mathematical model of action potentials of mouse sinoatrial node cells with molecular bases. Am. J. Physiol. Heart Circ. Physiol. 301, H945-H963. doi: 10.1152/ajpheart.00143.2010

Kozasa, Y., Nakashima, N., Ito, M., Ishikawa, T., Kimoto, H., Ushijima, K., et al. (2018). HCN4 pacemaker channels attenuate the parasympathetic response and stabilize the spontaneous firing of the sinoatrial node. J. Physiol. 596, 809-825. doi: 10.1113/JP275303

Kreitner, D. (1985). Electrophysiological study of the two main pacemaker mechanisms in the rabbit sinus node. Cardiovasc. Res. 19, 304-318. doi: 10. 1093/cvr/19.5.304

Lakatta, E. G., Maltsev, V. A., and Vinogradova, T. M. (2010). A coupled SYSTEM of intracellular $\mathrm{Ca} 2+$ clocks and surface membrane voltage clocks controls the timekeeping mechanism of the heart's pacemaker. Circ. Res. 106, 659-673. doi: 10.1161/CIRCRESAHA.109.206078

Lei, M., Brown, H. F., and Terrar, D. A. (2000). Modulation of delayed rectifier potassium current, $\mathrm{iK}$, by isoprenaline in rabbit isolated pacemaker cells. Exp. Physiol. 85, 27-35. doi: 10.1111/j.1469-445x.2000.01915.x

Lei, M., Jones, S. A., Liu, J., Lancaster, M. K., Fung, S. S., Dobrzynski, H., et al. (2004). Requirement of neuronal- and cardiac-type sodium channels for murine sinoatrial node pacemaking. J. Physiol. 559, 835-848. doi: 10.1113/jphysiol. 2004.068643

Lei, M., Zhang, H., Grace, A. A., and Huang, C. L. (2007). SCN5A and sinoatrial node pacemaker function. Cardiovasc. Res. 74, 356-365. doi: 10.1016/ j.cardiores.2007.01.009

Li, N., Csepe, T. A., Hansen, B. J., Dobrzynski, H., Higgins, R. S., Kilic, A., et al. (2015). Molecular mapping of sinoatrial node HCN channel expression in the human heart. Circ. Arrhythm. Electrophysiol. 8, 1219-1227. doi: 10.1161/ CIRCEP.115.003070

Li, N., Kalyanasundaram, A., Hansen, B. J., Artiga, E. J., Sharma, R., Abudulwahed, S. H., et al. (2020). Impaired neuronal sodium channels cause intranodal conduction failure and reentrant arrhythmias in human sinoatrial node. Nat. Commun. 11:512. doi: 10.1038/s41467-019-14039-8

Li, Y., Sirenko, S., Riordon, D. R., Yang, D., Spurgeon, H., Lakatta, E. G., et al. (2016). CaMKII-dependent phosphorylation regulates basal cardiac pacemaker function via modulation of local Ca2+ releases. Am. J. Physiol. Heart Circ. Physiol. 311, H532-H544. doi: 10.1152/ajpheart.00765.2015

Li, Y., Wang, F., Zhang, X., Qi, Z., Tang, M., Szeto, C., et al. (2012). betaAdrenergic stimulation increases Cav3.1 activity in cardiac myocytes through protein kinase A. PLoS One 7:e39965. doi: 10.1371/journal.pone.0039965

Liao, Z., Lockhead, D., Larson, E. D., and Proenza, C. (2010). Phosphorylation and modulation of hyperpolarization-activated HCN4 channels by protein kinase A in the mouse sinoatrial node. J. Gen. Physiol. 136, 247-258. doi: 10.1085/jgp. 201010488

Liu, J., Dobrzynski, H., Yanni, J., Boyett, M. R., and Lei, M. (2007). Organisation of the mouse sinoatrial node: structure and expression of HCN channels. Cardiovasc. Res. 73, 729-738. doi: 10.1016/j.cardiores.2006.11.016

Ludwig, A., Zong, X., Jeglitsch, M., Hofmann, F., and Biel, M. (1998). A family of hyperpolarization-activated mammalian cation channels. Nature 393, 587-591. doi: $10.1038 / 31255$

Ludwig, A., Zong, X., Stieber, J., Hullin, R., Hofmann, F., and Biel, M. (1999). Two pacemaker channels from human heart with profoundly different activation kinetics. EMBO J. 18, 2323-2329. doi: 10.1093/emboj/18.9.2323

MacDonald, E. A., Rose, R. A., and Quinn, T. A. (2020). Neurohumoral control of sinoatrial node activity and heart rate: insight from experimental models and findings from humans. Front. Physiol. 11:170. doi: 10.3389/fphys.2020. 00170

Maltsev, A. V., Yaniv, Y., Stern, M. D., Lakatta, E. G., and Maltsev, V. A. (2013). RyR-NCX-SERCA local cross-talk ensures pacemaker cell function at rest 
and during the fight-or-flight reflex. Circ. Res. 113, e94-e100. doi: 10.1161/ CIRCRESAHA.113.302465

Maltsev, V. A., and Lakatta, E. G. (2009). Synergism of coupled subsarcolemmal $\mathrm{Ca} 2+$ clocks and sarcolemmal voltage clocks confers robust and flexible pacemaker function in a novel pacemaker cell model. Am. J. Physiol. Heart Circ. Physiol. 296, H594-H615. doi: 10.1152/ajpheart.01118.2008

Mangoni, M. E., Couette, B., Bourinet, E., Platzer, J., Reimer, D., Striessnig, J., et al. (2003). Functional role of L-type Cav1.3 Ca2+ channels in cardiac pacemaker activity. Proc. Natl. Acad Sci. U.S.A. 100, 5543-5548. doi: 10.1073/ pnas.0935295100

Mangoni, M. E., and Nargeot, J. (2008). Genesis and regulation of the heart automaticity. Physiol. Rev. 88, 919-982. doi: 10.1152/physrev.00018.2007

Markram, H., Toledo-Rodriguez, M., Wang, Y., Gupta, A., Silberberg, G., and Wu, C. (2004). Interneurons of the neocortical inhibitory system. Nat. Rev. Neurosci. 5, 793-807. doi: 10.1038/nrn1519

Mesirca, P., Alig, J., Torrente, A. G., Muller, J. C., Marger, L., Rollin, A., et al. (2014). Cardiac arrhythmia induced by genetic silencing of 'funny' (f) channels is rescued by GIRK4 inactivation. Nat. Commun. 5:4664. doi: 10.1038/ ncomms5664

Mesirca, P., Fedorov, V. V., Hund, T. J., Torrente, A. G., Bidaud, I., Mohler, P. J., et al. (2021). Pharmacologic approach to sinoatrial node dysfunction. Annu. Rev. Pharmacol. Toxicol. 61, 757-778. doi: 10.1146/annurev-pharmtox031120-115815

Monfredi, O., Dobrzynski, H., Mondal, T., Boyett, M. R., and Morris, G. M. (2010). The anatomy and physiology of the sinoatrial node-a contemporary review. Pacing Clin. Electrophysiol. 33, 1392-1406. doi: 10.1111/j.1540-8159. 2010.02838.x

Narayanan, N., and Xu, A. (1997). Phosphorylation and regulation of the Ca(2+)pumping ATPase in cardiac sarcoplasmic reticulum by calcium/calmodulindependent protein kinase. Basic Res. Cardiol. 92(Suppl. 1), 25-35. doi: 10.1007/ BF00794065

Narayanan, R., and Johnston, D. (2008). The h channel mediates location dependence and plasticity of intrinsic phase response in rat hippocampal neurons. J. Neurosci. 28, 5846-5860. doi: 10.1523/JNEUROSCI.0835-08. 2008

Nikmaram, M. R., Boyett, M. R., Kodama, I., Suzuki, R., and Honjo, H. (1997). Variation in effects of Cs+, UL-FS-49, and ZD-7288 within sinoatrial node. Am. J. Physiol. 272, H2782-H2792. doi: 10.1152/ajpheart.1997.272.6. $\mathrm{H} 2782$

Nolan, M. F., Malleret, G., Dudman, J. T., Buhl, D. L., Santoro, B., Gibbs, E., et al. (2004). A behavioral role for dendritic integration: HCN1 channels constrain spatial memory and plasticity at inputs to distal dendrites of CA1 pyramidal neurons. Cell 119, 719-732. doi: 10.1016/j.cell.2004.11.020

Noma, A., Kotake, H., and Irisawa, H. (1980). Slow inward current and its role mediating the chronotropic effect of epinephrine in the rabbit sinoatrial node. Pflugers Arch. 388, 1-9. doi: 10.1007/BF00582621

Noma, A., Morad, M., and Irisawa, H. (1983). Does the "pacemaker current" generate the diastolic depolarization in the rabbit SA node cells? Pflugers Arch. 397, 190-194. doi: 10.1007/BF00584356

Pauza, D. H., Rysevaite, K., Inokaitis, H., Jokubauskas, M., Pauza, A. G., Brack, K. E., et al. (2014). Innervation of sinoatrial nodal cardiomyocytes in mouse. A combined approach using immunofluorescent and electron microscopy. J. Mol. Cell. Cardiol. 75, 188-197. doi: 10.1016/j.yjmcc.2014.07.016

Peters, C. H., Liu, P. W., Morotti, S., Gantz, S. C., Grandi, E., Bean, B. P., et al. (2021). Bi-directional flow of the funny current (If) during the pacemaking cycle in murine sinoatrial node myocytes. bioRxiv [Preprint]. doi: 10.1101/2021. 03.10 .434820

Rigg, L., Heath, B. M., Cui, Y., and Terrar, D. A. (2000). Localisation and functional significance of ryanodine receptors during beta-adrenoceptor stimulation in the guinea-pig sino-atrial node. Cardiovasc. Res. 48, 254-264. doi: 10.1016/s00086363(00)00153-x

Robinson, R. B., and Siegelbaum, S. A. (2003). Hyperpolarization-activated cation currents: from molecules to physiological function. Annu. Rev. Physiol. 65, 453-480. doi: 10.1146/annurev.physiol.65.092101.142734

Sadeh, S., and Clopath, C. (2021). Inhibitory stabilization and cortical computation. Nat. Rev. Neurosci. 22, 21-37. doi: 10.1038/s41583-020-00390-z

Sanchez-Quintana, D., Cabrera, J. A., Farre, J., Climent, V., Anderson, R. H., and Ho, S. Y. (2005). Sinus node revisited in the era of electroanatomical mapping and catheter ablation. Heart 91, 189-194. doi: 10.1136/hrt.2003.03 1542

Saponaro, A., Cantini, F., Porro, A., Bucchi, A., Difrancesco, D., Maione, V., et al. (2018). A synthetic peptide that prevents cAMP regulation in mammalian hyperpolarization-activated cyclic nucleotide-gated (HCN) channels. Elife 7:e35753. doi: 10.7554/eLife.35753

Schulze-Bahr, E., Neu, A., Friederich, P., Kaupp, U. B., Breithardt, G., Pongs, O., et al. (2003). Pacemaker channel dysfunction in a patient with sinus node disease. J. Clin. Invest. 111, 1537-1545. doi: 10.1172/JCI 16387

Shan, J., Kushnir, A., Betzenhauser, M. J., Reiken, S., Li, J., Lehnart, S. E., et al. (2010). Phosphorylation of the ryanodine receptor mediates the cardiac fight or flight response in mice. J. Clin. Invest. 120, 4388-4398. doi: 10.1172/JCI3 2726

Stieber, J., Herrmann, S., Feil, S., Loster, J., Feil, R., Biel, M., et al. (2003). The hyperpolarization-activated channel HCN4 is required for the generation of pacemaker action potentials in the embryonic heart. Proc. Natl. Acad. Sci. U.S.A. 100, 15235-15240. doi: 10.1073/pnas.2434235100

Swaminathan, P. D., Purohit, A., Soni, S., Voigt, N., Singh, M. V., Glukhov, A. V., et al. (2011). Oxidized CaMKII causes cardiac sinus node dysfunction in mice. J. Clin. Invest. 121, 3277-3288. doi: 10.1172/JCI57833

Torrente, A. G., Zhang, R., Zaini, A., Giani, J. F., Kang, J., Lamp, S. T., et al. (2015). Burst pacemaker activity of the sinoatrial node in sodium-calcium exchanger knockout mice. Proc. Natl. Acad. Sci. U.S.A. 112, 9769-9774. doi: 10.1073/pnas. 1505670112

Tsutsui, K., Monfredi, O. J., Sirenko-Tagirova, S. G., Maltseva, L. A., Bychkov, R., Kim, M. S., et al. (2018). A coupled-clock system drives the automaticity of human sinoatrial nodal pacemaker cells. Sci. Signal. 11:eaa7608. doi: 10.1126/ scisignal.aap7608

van der Heyden, M. A., Wijnhoven, T. J., and Opthof, T. (2005). Molecular aspects of adrenergic modulation of cardiac L-type Ca2+ channels. Cardiovasc. Res. 65, 28-39. doi: 10.1016/j.cardiores.2004.09.028

Verheijck, E. E., Van Kempen, M. J., Veereschild, M., Lurvink, J., Jongsma, H. J., and Bouman, L. N. (2001). Electrophysiological features of the mouse sinoatrial node in relation to connexin distribution. Cardiovasc. Res. 52, 40-50. doi: 10. 1016/s0008-6363(01)00364-9

Verheijck, E. E., Wilders, R., and Bouman, L. N. (2002). Atrio-sinus interaction demonstrated by blockade of the rapid delayed rectifier current. Circulation 105, 880-885. doi: $10.1161 /$ hc0702.104128

Verkerk, A. O., and Wilders, R. (2015). Pacemaker activity of the human sinoatrial node: an update on the effects of mutations in HCN4 on the hyperpolarizationactivated current. Int. J. Mol. Sci. 16, 3071-3094. doi: 10.3390/ijms1602 3071

Vinogradova, T. M., Bogdanov, K. Y., and Lakatta, E. G. (2002). beta-Adrenergic stimulation modulates ryanodine receptor $\mathrm{Ca}(2+)$ release during diastolic depolarization to accelerate pacemaker activity in rabbit sinoatrial nodal cells. Circ. Res. 90, 73-79. doi: 10.1161/hh0102.102271

Vinogradova, T. M., Brochet, D. X., Sirenko, S., Li, Y., Spurgeon, H., and Lakatta, E. G. (2010). Sarcoplasmic reticulum Ca2+ pumping kinetics regulates timing of local $\mathrm{Ca} 2+$ releases and spontaneous beating rate of rabbit sinoatrial node pacemaker cells. Circ. Res. 107, 767-775. doi: 10.1161/CIRCRESAHA.110. 220517

Vinogradova, T. M., Lyashkov, A. E., Zhu, W., Ruknudin, A. M., Sirenko, S., Yang, D., et al. (2006). High basal protein kinase A-dependent phosphorylation drives rhythmic internal $\mathrm{Ca} 2+$ store oscillations and spontaneous beating of cardiac pacemaker cells. Circ. Res. 98, 505-514. doi: 10.1161/01.RES.0000204575. 94040.d1

Vinogradova, T. M., Tagirova Sirenko, S., and Lakatta, E. G. (2018). Unique $\mathrm{Ca}(2+)$-cycling protein abundance and regulation sustains local $\mathrm{Ca}(2+)$ releases and spontaneous firing of rabbit sinoatrial node cells. Int. J. Mol. Sci. 19:2173. doi: $10.3390 /$ ijms 19082173

Vinogradova, T. M., Zhou, Y. Y., Bogdanov, K. Y., Yang, D., Kuschel, M., Cheng, H., et al. (2000). Sinoatrial node pacemaker activity requires $\mathrm{Ca}(2+) /$ calmodulindependent protein kinase II activation. Circ. Res. 87, 760-767. doi: 10.1161/01. res.87.9.760

Vinogradova, T. M., Zhou, Y. Y., Maltsev, V., Lyashkov, A., Stern, M., and Lakatta, E. G. (2004). Rhythmic ryanodine receptor Ca2+ releases during diastolic depolarization of sinoatrial pacemaker cells do not require membrane 
depolarization. Circ. Res. 94, 802-809. doi: 10.1161/01.RES.0000122045. $55331.0 \mathrm{~F}$

Wahl-Schott, C., and Biel, M. (2009). HCN channels: structure, cellular regulation and physiological function. Cell. Mol. Life Sci. 66, 470-494. doi: 10.1007/s00018008-8525-0

Wahl-Schott, C., Fenske, S., and Biel, M. (2014). HCN channels: new roles in sinoatrial node function. Curr. Opin. Pharmacol. 15, 83-90. doi: 10.1016/j.coph. 2013.12.005

Wu, Y., and Anderson, M. E. (2014). CaMKII in sinoatrial node physiology and dysfunction. Front. Pharmacol. 5:48. doi: 10.3389/fphar.2014.00048

Wu, Y., Gao, Z., Chen, B., Koval, O. M., Singh, M. V., Guan, X., et al. (2009). Calmodulin kinase II is required for fight or flight sinoatrial node physiology. Proc. Natl. Acad. Sci. U.S.A. 106, 5972-5977. doi: 10.1073/pnas.080642 2106

Yanagihara, K., and Irisawa, H. (1980). Inward current activated during hyperpolarization in the rabbit sinoatrial node cell. Pflugers Arch. 385, 11-19. doi: 10.1007/BF00583909
Zagotta, W. N., Olivier, N. B., Black, K. D., Young, E. C., Olson, R., and Gouaux, E. (2003). Structural basis for modulation and agonist specificity of HCN pacemaker channels. Nature 425, 200-205. doi: 10.1038/nature01922

Zhou, Z., and Lipsius, S. L. (1993). Na(+)-Ca2+ exchange current in latent pacemaker cells isolated from cat right atrium. J. Physiol. 466, 263-285.

Conflict of Interest: The authors declare that the research was conducted in the absence of any commercial or financial relationships that could be construed as a potential conflict of interest.

Copyright $\odot 2021$ Hennis, Rötzer, Piantoni, Biel, Wahl-Schott and Fenske. This is an open-access article distributed under the terms of the Creative Commons Attribution License (CC BY). The use, distribution or reproduction in other forums is permitted, provided the original author(s) and the copyright owner(s) are credited and that the original publication in this journal is cited, in accordance with accepted academic practice. No use, distribution or reproduction is permitted which does not comply with these terms. 